\title{
EFFECTIVENESS OF REPRODUCTIVE HEALTH AND AIDS EDUCATION AMONG ADOLESCENT GIRLS IN UDUPI TALUK, INDIA
}

\section{ABSTRACT}

An intervention study was undertaken among adolescent girls in age group 16-19 years, studying in preuniversity colleges, in Udupi town in Karnataka State, India, to asses the impact of health education on knowledge regarding reproductive health \& AIDS. 4 pre-university colleges were randomly selected in Udupi town. There were 551 students present for the pretest and 548 in the post test. Knowledge was assessed at the beginning of the study with the help of a questionnaire that was duly pre-tested. Based on the results of this baseline survey, a health education programme was developed and implemented after a week in each of the selected colleges. A second visit was made to the same colleges after one month of conducting health education programme for post-test The same questionnaire was administered to assess the impact of health education. Significant increase in knowledge about adolescence, menarche, pregnancy, delivery, immunization and various aspects of AIDS following health education. This study has shown that there is a beneficial effect of health education on the knowledge and awareness related to reproductive health and AIDS among adolescent girls.

Key Words: Reproductive Health, AIDS, Health Education.

\section{INTRODUCTION}

Adolescence as the period between the ages of 10-19 years, encompassing the entire continuum of transition from childhood to adulthood. It is the most critical period of development, second only to early childhood, when they acquire new capacities and are faced with many new situations. This period presents not only opportunities for progress but also risks to health and wellbeing. 1

Adolescents make up about $20 \%$ of the world's population and their numbers are expected to grow world wide by at least 60 million between $1995-2025 .^{2}$ In India $4.8 \%$ of the total population is in the $15-19$ year age group. ${ }^{3}$

Adolescent health and nutrition are important issues, since it reflects the health status of adults of tomorrow. The health profile of adolescent girls has a great impact on their later reproductive performance, which is to bring about healthy motherhood and decreased maternal and infant mortality. Hence neglect of adolescents can lead to problems, both immediately and in the years ahead.

More adolescents today than in the past generations are involved in multiple health risk behaviours and at earlier ages. The mean age of onset of puberty is continuing to decline while the mean age of marriage is rising. This implies a longer period of possible unprotected sexual activity in unmarried adolescents, who have little access to contraceptives service, particularly in developing countries. This increasing unprotected sex brings in the danger of too early and unwanted pregnancy, induced abortion often in hazardous conditions, sexually transmitted diseases and HIV infection resulting in AIDS.

* Manipal College of Medical Science, Pokhara, Nepal.

** Kasturba Medical College, Manipal.

Address for correspondence : Dr. Lochana Shrestha

Manipal College of Medical Science, Pokhara, Nepal

Email: shresthalochana@yahoo.com 
These burgeoning health problems among adolescents make them a high risk group. Information about reproduction and sexuality if made available to them will go a long way in increasing the ability of adolescents to deal with their health problems. This study was therefore launched to determine the impact of health education on the knowledge towards reproductive health \& AIDS.

\section{MATERIALS AND METHODS}

This study was conducted among adolescent girls in age group 16-19 years, studying in pre-university colleges, in Udupi town in Karnataka State, India. It was an intervention study conducted over a 6 months period from 1 st June to 31 st November 1999.

There are 10 pre university colleges in Udupi town. Among them 4 pre university colleges were selected randomly by lottery method. Adolescent girls of these selected colleges constituted the study subjects. Knowledge regarding reproductive health \& AIDS was assessed at the beginning of the study with the help of a questionnaire that was duly pre-tested. Various aspects of reproductive health such as normal menstrual cycle, menarche, age at marriage, normal pregnancy, consequences of adolescent pregnancy were covered in the questionnaire. Knowledge related to diet during pregnancy, breast feeding, safe sex \& contraceptive methods as well as a host of other questions related to various modes of transmission of AIDS, its prevention and control were also included.

Based on the results of this baseline survey, training needs of the students were identified. Accordingly a health education programme was developed. After a week in each of the selected colleges the team of three peoples including doctor and two health educators visited to conduct health education regarding reproductive health and AIDS. For health education audio visual aids like video tape, pamphlets, flip charts were used. After education cross questions session was included to clear the confusion of students.

A second visit was made to the same colleges after three months of conducting health education programme. At this time same questionnaire was administered to assess the impact of health education on knowledge related to reproductive health and AIDS. Hence awareness regarding reproductive health and AIDS among adolescent girls was measured simply by administering questionnaire. Three months interval between health education and assessment was chosen following the same study conducted in India. ${ }^{4}$

The findings have been summarized in the tables using statistical methods such as proportions and Chi-square test.

Table I : Knowledge about Menstruation, Menarche, Age at marriage and Adolescent Pregnancy among adolescent girls

\begin{tabular}{l|ccc|c|c}
\hline \multirow{2}{*}{\multicolumn{1}{c}{ Knowledge }} & \multicolumn{2}{c}{$\begin{array}{c}\text { Pretest (n=551) } \\
\text { Correctly answered }\end{array}$} & \multicolumn{2}{c|}{$\begin{array}{c}\text { Post-test (n=548) } \\
\text { Correctly answered }\end{array}$} & P-value \\
\cline { 2 - 7 } & No. & \% & No. & \% & \\
\hline Usual age of Marriage & 351 & 63.7 & 468 & 85.4 & $<0.001$ \\
\hline Duration of menstrual cycle & 349 & 63.3 & 445 & 81.2 & $<0.001$ \\
Age of marriage & 517 & 93.8 & 835 & 98.2 & $<0.001$ \\
For girls \& boys III effects of & 197 & 35.2 & 428 & 78.1 & $<0.001$ \\
adolescent pregnancy & & & & & \\
\hline
\end{tabular}

Table II : Knowledge about Menstruation, Menarche, Age at marriage and Adolescent Pregnancy among adolescent girls

\begin{tabular}{|c|c|c|c|c|c|}
\hline \multirow[t]{2}{*}{ Knowledge } & \multicolumn{2}{|c|}{$\begin{array}{c}\text { Pretest }(\mathrm{n}=551) \\
\text { Correctly answered }\end{array}$} & \multicolumn{2}{|c|}{$\begin{array}{c}\text { Post-test }(\mathrm{n}=548) \\
\text { Correctly answered }\end{array}$} & \multirow[t]{2}{*}{$\overline{P \text {-value }}$} \\
\hline & No. & $\%$ & No. & $\%$ & \\
\hline $\begin{array}{l}\text { Pregnancy as a normal physiological } \\
\text { phenomenon }\end{array}$ & 424 & 76.9 & 464 & 84.6 & $<0.001$ \\
\hline Diet during pregnancy & 187 & 33.9 & 331 & 60.4 & $<0.001$ \\
\hline $\begin{array}{l}\text { Importance of health checkups in } \\
\text { pregnancy }\end{array}$ & 170 & 30.9 & 379 & 69.2 & $<0.001$ \\
\hline Delivery by trained personnel & 323 & 58.6 & 488 & 89.0 & $<0.001$ \\
\hline Institutional delivery & 481 & 87.3 & 538 & 98.2 & $<0.001$ \\
\hline Initiation of breast feeding & 245 & 44.4 & 414 & 75.5 & $<0.001$ \\
\hline Exclusive breast feeding & 75 & 13.6 & 243 & 44.3 & $<0.001$ \\
\hline Weaning & 261 & 47.3 & 403 & 73.5 & $<0.001$ \\
\hline Immunization of Infants & 40 & 7.3 & 440 & 80.2 & $<0.001$ \\
\hline Age to have the first child & 492 & 89.2 & 505 & 92.1 & 0.102 \\
\hline Use of family planning before marriage & 91 & 16.5 & 192 & 35.0 & $<0.001$ \\
\hline
\end{tabular}


Table III : Knowledge about AIDS among adolescent girls

\begin{tabular}{lc|c|c|cc}
\hline \multirow{2}{*}{ Knowledge } & \multicolumn{2}{c|}{$\begin{array}{c}\text { Pretest } \mathbf{( n = 5 5 1 )} \\
\text { Correctly answered }\end{array}$} & \multicolumn{2}{c}{$\begin{array}{c}\text { Post-test (n=548) } \\
\text { Correctly answered }\end{array}$} & P-value \\
\cline { 2 - 6 } & No. & $\mathbf{\%}$ & No. & \% & \\
\hline AIDS is preventable & 155 & 28.1 & 453 & 82.6 & $<0.001$ \\
\hline Transmission through unprotected sex & 427 & 77.5 & 461 & 84.1 & 0.005 \\
\hline Transmission by kissing & 94 & 17.0 & 398 & 72.6 & $<0.001$ \\
\hline Transmission through blood & 346 & 62.7 & 443 & 79.1 & $<0.001$ \\
\hline Transmission through infected needle & 333 & 60.4 & 434 & 79.1 & $<0.001$ \\
\hline Transmission by bites & 321 & 58.2 & 472 & 86.1 & $<0.001$ \\
\hline Transmission by contaminated water & 294 & 53.4 & 401 & 73.1 & $<0.001$ \\
\hline Transmission by using swimming pool & 353 & 64.0 & 387 & 70.6 & 0.020 \\
\hline Prevention of AIDS by using condom & 285 & 51.7 & 390 & 71.2 & $<0.001$ \\
\hline
\end{tabular}

\section{OBSERVATIONS AND DISCUSSION}

There were 551 students present for the pretest, where as in the post test there were only 548 students.

Table I show that a majority of students $(93.8 \%)$ were aware of the correct age of marriage for both girls and boys. Only $35.2 \%$ of students were aware about consequences of adolescent pregnancy. However, there was an absolute increase in number of students with correct knowledge about adolescent pregnancy after health education. There was also a significant rise in the knowledge regarding menarche and menstrual period after intervention. Most students were aware that hospital was the best place for delivery $(87.2 \%)$ and also had correct knowledge regarding age to have first child $(89.2 \%)$. Only $7.2 \%$ of the students knew about infant immunization and $13.6 \%$ of the students had correct idea about exclusive breast feeding. $33.9 \%$ of students had correct knowledge about diet during pregnancy. These findings are consistent with the findings of a study conducted in a rural south Indian Population by S Chandrakala et al. ${ }^{4}$ Following health education there was a significant increase in the knowledge regarding pregnancy, breast feeding and contraceptive methods (Table II).

Table III shows that only $28.1 \%$ of study subjects were initially aware that AIDS is preventable and this proportion increased to $82.6 \%$ after health education. Half of the students knew that AIDS could be prevented by using condom. Further there was a significant increase in the knowledge regarding mode of transmission and prevention of AIDS following health education.

This study has demonstrated the effect of health education in bringing about improvement in the awareness regarding reproductive health and AIDS among adolescent girls.

Hence there is a need to conduct Health education programmes in high schools and colleges specifically directed towards adolescent girls. This would go a long way in strengthening the strategies for reproductive and child health.

\section{REFERENCES}

1 Vorld Heal th Ogani zati on. Adbl escence the Gri ti cal Phase New La hi : Regi onal Offi ce for Sauth-East Asi a; 1997.

2 Arthur BE, Patrica L I ntegati ng conprehensi ve adbl escent prevent i ve servi ces i nto routi ne nedi ci ne care. I n:

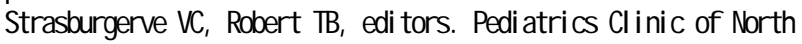
Aneri ca. 1997; 44(6): 1366.

3 Coverment of I nd a. Census of I ndi a 1991, Seri es- 1 Anol ya Ratna Nanda, Regi strar General \& Census Comnissi oner, Ind a. 1991

4 Mry P, Chandrakal a S, J ayal akshni S, et al. Status of adbl escent girls in a rura Ind an popul ation Ind an J. Naterna and Child Heal th 1991; 2(2): 60-6. 